\title{
Difficulties with Workplace Support for a Patient with Frontotemporal Dementia: A Case Report
}

\author{
Mika Kumai ${ }^{1,2}$ \\ Keiichi Kumai ${ }^{3}$ \\ Kei Nakamura $\mathbb{1}^{3}$ \\ Shigeo Kinomura ${ }^{4}$ \\ Kenichi Meguro 2,3,5 \\ 'The Friend Pharmacy, Osaki, Miyagi, \\ Japan; ${ }^{2}$ Cyclotron Radioisotope Center, \\ Tohoku University, Sendai, Miyagi, Japan; \\ ${ }^{3}$ Geriatric Behavioral Neurology Project, \\ New Industry Creation Hatchery Center, \\ Tohoku University, Sendai, Miyagi, Japan; \\ ${ }^{4}$ Clinic of Imaging Medicine and Brain \\ Health, Sendai, Miyagi, Japan; ${ }^{5}$ Tohoku \\ University Graduate School of Medicine, \\ Sendai, Miyagi, Japan
}

Correspondence: Kenichi Meguro

Tohoku University New Industry

Creation Hatchery Center, 4-I, Seiryo-

machi, Aoba-ku, IDAC, Sendai, 980-8575,

Japan

Tel +8I-22-7I 7-7359

Email kenichi.meguro.e6@tohoku.ac.jp

\begin{abstract}
A 59-year-old, right-handed woman made many mistakes in her job in a pharmacy, despite having considerable experience working in this setting. She had a cando attitude, but also showed no sign of remorse when she failed. Other staff grew impatient with her and she was diagnosed with frontotemporal dementia based on clinical and brain imaging findings. After diagnosis, other staff understood that the disease was the cause of her difficulties, and her work tasks and hours were changed to fit with her stereotypical behavior. This support in the workplace made it possible for her to continue her job.
\end{abstract}

Keywords: workspace support, frontotemporal dementia, dementia

\section{Introduction}

In Japan, the Ministry of Health, Labour and Welfare promotes approaches and policies on senility based on a report entitled "Improved healthcare and quality of life for dementia patients". ${ }^{1}$ Continuous team support with a job coach is provided from the time patients find employment until they have established a stable working environment in a project to support handicapped persons, their families, and employers, based on the disability level. ${ }^{2}$ However, generally patients with dementia do not receive early treatment because they have insufficient understanding of their dementia, and do not visit a hospital. Thus, they do not receive job coaching because they are not diagnosed with dementia.

There are few reports on working support for patients with dementia, ${ }^{3}$ contrary to that of Schizophrenia. ${ }^{4}$ Among dementing diseases, frontotemporal dementia (FTD $)^{5,6}$ is a very special disease, and patients with the disease show "going-my-way behaviors," almost no self-awareness of their disabilities compared with those with Alzheimer disease. Thus, the workspace support is so difficult and no remarkable case are reported.

This report showed that a patient with $\mathrm{FTD}^{6}$ received workplace support from the time of joining a company until she chose voluntary retirement.

\section{The Case}

\section{Past Histories and Present Situation}

A 59-year-old right-handed female with 12 years of schooling had a history of diabetes and depression. After 4 years as a general office worker after graduation from high school, she got married and stayed at home. After raising 3 children, she went back to work as a medical clerk at a hospital when she was 37 years old. At this time, her husband began to do most of the housework. However, she maintained her ability at 
Table I Work History of the Subject

\begin{tabular}{|l|l|l|l|l|}
\hline Workplace & Working Period & Job type & Length of Service & Leaving Reason \\
\hline Company A & April 1974 & Clerk & 4 years and 8 months & Got married \\
Dispensing pharmacy B & August 1995 & Dispensing clerk & 3 years and II months & Closing of the pharmacy \\
Dispensing pharmacy C & September 1999 & Dispensing clerk & 2 years and 2 months & Voluntary resignation \\
Dispensing pharmacy D & October 200I & Dispensing clerk & 7 years and 7 months & Voluntary resignation \\
Dispensing pharmacy E & January 20II & Dispensing clerk & I year and I month & Voluntary resignation \\
Dispensing pharmacy F & June 2012 & Dispensing clerk & I year and 5 months & Voluntary resignation \\
Dispensing pharmacy G & October 20I3 & Dispensing clerk & I year and 4 months & Voluntary resignation \\
Dispensing pharmacy H & October 20I5 & Dispensing clerk & No data & No data \\
\hline
\end{tabular}

Notes: Some of this information is unclear because these are self-reported data. The subject said that she worked for dispensing pharmacies without making mistakes. However, during and after working for dispensing pharmacy E, she repeatedly changed workplaces every 1.5 years. She said that these changes were due to workplace bullying in pharmacies $E, F$ and $G$.

housework by making a lunch bag for her youngest child. Table 1 shows the working history of the subject.

She changed jobs 6 times after she began to work at a pharmacy. She said that she made no mistakes in her work, but this was self-reported. She had begun to change her workplace repeatedly every 1.5 years since joining pharmacy E. She said she left pharmacies E, F and $\mathrm{G}$ due to bullying at these workplaces.

In an interview, the subject said, "You do not need to teach me how to use the device because I have used the same type before. I think I will be an industry-ready worker here because I have experience". Thus, supervising pharmacist A at pharmacy $\mathrm{H}$ decided to employ the subject based on this interview.

The subject was instructed on the details of the business and how to use devices by dispensing clerk A based on the experience of the clerk for 2 weeks after joining pharmacy $\mathrm{H}$. However, when she failed to use a device, she said in a nonchalant manner, "I do not know how to use this device. I can't possibly use it because no one taught me how to use it." In addition, when dispensing clerks $\mathrm{B}$ and $\mathrm{C}$ assisted her by explaining how to use the device again, she pretended she knew how to use it and disrupted the explanation by saying "It's OK." However, she continued to make mistakes and frequently received warnings from supervising pharmacist A. Her work resulted in mistakes made while operating a cash register and a receipt computer, in management of stock quantity and omission of a report on insufficient stock and ordering of products. Supervising pharmacist A bemoaned that her work was worse than that of an unexperienced clerk, although she was hired as an industry-ready experienced clerk based on her resume and interview. Dispensing clerks B and C became tired of having to follow up her work continually. Other co-workers were also irritated and this produced a poor working environment.
Dispensing clerks B and C often tried to improve her work, but the subject did not change her attitude, even she was taught tasks she was unable to do. Dispensing clerk B reported the situation to supervising pharmacist $\mathrm{A}$, who was continually upset with her. The subject talked to dispensing clerk B, with whom she had a comparatively good relationship, about her problems at work every day. The subject said that she was disliked by all co-workers. Supervising pharmacist A, who did not know how to treat her, began to consult with dispensing clerk B about the subject.

The subject had characteristics of (1) repeating mistakes as she did work on her own, (2) not working correctly even after repeated instructions, saying, "I cannot do this because no one taught me" and "I made this mistake because this was different from the way I did it in a previous workplace," and (3) showing no remorse for her mistakes, saying, "I make mistakes because I become nervous when supervising pharmacist A is beside me."

In hearing from the subject about her daily activities, she said that she ate breakfast at 5:40 every morning and went to work using a bus that she had used to go to her previous workplace. This took 1.5 hours, although the journey was only 15 minutes by bicycle (and 30 minutes by direct bus). She bought the same drink at the same convenience store. Based on observations by dispensing clerks $\mathrm{B}$ and $\mathrm{C}$, she had the same daily pattern: for example, she arrived at the pharmacy at 8:10 and punched a time clock at 8:17 every day to prepare for opening the pharmacy, even if she was on an early or late shift.

\section{Neuropsychological and Neuroimaging Examinations}

At the medical checkup, the subject received neuropsychological examinations with the Cognitive Abilities Screening 
Instrument (CASI), Mini-Mental State Examination (MMSE), and Trail Making Test A and B (TMT-A and TMT-B). Neuroimaging was performed using MRI and SPECT. Cerebral blood flow (CBF) was evaluated using an easy Z-score imaging system (eZIS) for SPECT images. A specialist interviewed her family about her daily life, and also asked the president of the dispensing pharmacy about her working situation at the pharmacy.

The results of the examinations were CASI: 87/100, MMSE: 27/30, TMT-A: 35 s, and TMT-B: 135 s. These results indicated no significant decreases of general cognitive function and executive function. MRI showed no vascular diseases. eZIS images showed no reduction of $\mathrm{CBF}$ in the posterior cingulate gyrus and precuneus, which are characteristic areas in Alzheimer patients, but reduced $\mathrm{CBF}$ in both frontal lobes and surrounding areas (Figure 1).

\section{Informed Consent}

Written informed consent from the patient and her family was obtained after they received a sufficient explanation of the study. The patient and her family provided written informed consent for the case details to be published.

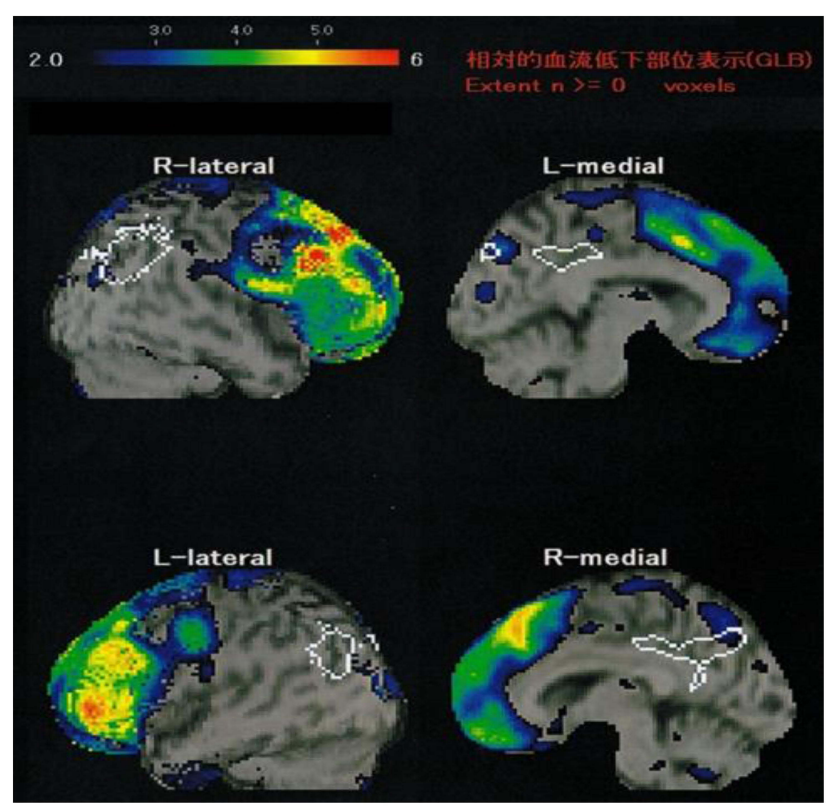

Figure I eZIS imaging findings for the subject.

Notes: Colored areas show decreased blood flow compared to data for healthy persons. Areas indicated by white lines are characteristic of those with decreased blood flow in patients with Alzheimer disease. In this case, decreased blood flow was found in both frontal lobes and surrounding areas, but not in the posterior cingulate cortex and precuneus, which are common areas with decreased blood flow in Alzheimer disease.

Abbreviations: R, Right; L, Left.
The Ethical Committee of the Friend Pharmacy Co. approved the case details to be published.

\section{Diagnosis}

Based on the examinations and information from her family and workplace, the specialist diagnosed FTD. ${ }^{6}$

\section{Intervention}

Dispensing clerk B was concerned about the difficult atmosphere in the workplace and thought that this might be improved if the subject was criticized by supervising pharmacist A less frequently. For this, it was important to increase the success rate of her work. Thus, dispensing clerk B became aware of the need for both work support (1) and understanding of co-workers. Dispensing clerk B classified her work into simple and complex tasks based on observation of her working approach (Table 2).

Dispensing clerk B proposed work tasks, working hours, and interactions with the subject, using the following approach based on observation of her past behavior:

(1) tasks should be divided into those the subject could and could not do

(2) tasks that the subject could do should be allocated to the subject

(3) of tasks she could not do, those that she might partly be able to do should be identified

(4) tasks for the subject should be reduced to avoid as many mistakes as possible

(5) tasks should be organized so that the subject could do the same work every day

Regarding working hours, these were fixed so that the subject always started her work on an early shift. In addition, she tended to have negative feelings, such as the idea of being disliked or bullied. She said she repeated mistakes due to these negative feelings. Thus, other co-workers at the pharmacy tried to be more sympathetic by using fewer negative words during conversations with the subject.

Dispensing clerk B proposed the following training for co-workers to supervising pharmacist A:

(1) provision of information on dementia

(2) recognition of differences in mistakes made by the subject

(3) avoidance of risks by confirming each element of her work tasks

(4) establishing a routine with fixed shift and break times to allow the subject to do the same work every day

Dispensing clerk B also provided the following personal support by: 
Table 2 List of Work Contents

\begin{tabular}{|c|c|c|c|}
\hline \multirow[t]{9}{*}{ Simple tasks } & Turning on the lights in all rooms and running the computer & Serial work & $\circ$ \\
\hline & Receipt and confirmation of delivered products & Serial work & $\circ$ \\
\hline & Handling of phone calls & Serial work & $\circ$ \\
\hline & Receipt of prescriptions & Serial work & $\circ$ \\
\hline & Going to the bank (acceptance and delivery) & Serial work & $\circ$ \\
\hline & Cleaning & Serial work & $\circ$ \\
\hline & Confirmation of dispensing records & Serial work & $\circ$ \\
\hline & Operation of a phone (release of transfer mode) (different from previous workplaces) & Serial work & $\Delta$ \\
\hline & Supplementation of consumables (different from previous workplaces) & Serial work & $\Delta$ \\
\hline \multirow{11}{*}{$\begin{array}{l}\text { Complex } \\
\text { work }\end{array}$} & Confirmation of stock and taking orders & Serial/parallel work & $\mathrm{x}$ \\
\hline & Preparation for persons scheduled to come from other hospitals & Serial/parallel/planning work & $x$ \\
\hline & $\begin{array}{l}\text { Audit (confirmation of drug information, contents of prescriptions, manufacturers, number of } \\
\text { tablets, etc.) }\end{array}$ & Serial/parallel/planning work & $\mathrm{x}$ \\
\hline & $\begin{array}{l}\text { Input work on receipt computer (input of prescriptions, printing of drug information and } \\
\text { prescriptions, etc.) }\end{array}$ & Serial/parallel/planning work & $x$ \\
\hline & Operation of cash register & Serial/parallel/planning work & $\mathrm{x}$ \\
\hline & Management of sales & Serial/planning work & $\mathrm{x}$ \\
\hline & Request for receipts & Serial/planning work & $\mathrm{x}$ \\
\hline & Filing work (with various classification methods) & Serial/planning work & $x$ \\
\hline & Divided sales & Serial/parallel/planning work & $x$ \\
\hline & Orders & Serial/parallel/planning work & $\mathrm{x}$ \\
\hline & Closing work* & Serial/parallel/planning work & $x$ \\
\hline
\end{tabular}

Notes: $\odot$ : almost no mistakes, $\Delta$ : some mistakes, $\mathrm{X}$ : frequent mistakes *closing work: plural procedures to be completed in a limited time, such as turning off the power of all devices, transfer of all data in the day, storage of proceeds, and locking the door until the end of the workday. Simple work included only serial tasks, while complex work required several executive functions. In addition, the subject was requested to do some tasks, such as release of phone transfer and supplementation of consumables, in ways that differed from those in her previous workplaces. Therefore, she sometimes made mistakes even in serial work.

(1) decreasing anxiety among co-workers by listening to their concerns that their work might increase when working with the subject

(2) taking a neutral stance when the subject and other co-workers became emotional about problems that had developed between them

(3) reporting actual situations to the president

\section{Results of the Intervention}

The subject began to gradually understand her role in the pharmacy. Her work became more routine, which enabled her to work more stably. She had fewer negative comments and sometimes started to smile.
Co-workers developed a deeper understanding of dementia and had fewer reasons to blame her for mistakes. They gave her tasks one by one and checked her work in each task. Thus, corrections required for her work decreased. By fixing the time schedule of the subject, anxiety of co-workers was reduced because they could easily control their work.

Since dispensing clerks observed the behavior of the subject during the work support, all workers could discuss ideas for work improvement together. They also began to enjoy conversations with the subject because the anxieties of the subject and co-workers were reduced. The workplace atmosphere improved compared with that before the diagnosis. 


\section{Discussion}

The subject visited a specialist and subsequently received workplace support. In addition, education on dementia was provided to co-workers, which allowed them to understand that the problems of the subject were caused by the disease, and not by her character. This resulted in a better response to the subject, and knowledge about dementia among her co-workers was particularly important in this case. Support for the subject included decreased and simplified work tasks and assistance with her work, but the subject then complained that, "I cannot do my work as I like." However, even if the subject was unhappy about the limitations on her work, it was clear that an increase in satisfaction of the subject would also increase the workload on her co-workers. This might decrease their satisfaction, and this was observed in situations that occurred before the diagnosis, when other co-workers felt uptight. In this case, appropriate countermeasures were taken in an organized way because dispensing clerk B had knowledge of dementia. However, other coworkers did not immediately act appropriately due to lack of knowledge about dementia, which often placed dispensing clerk $\mathrm{B}$ in a dilemma between the subject and other co-workers. The satisfaction of the subject is important but work volume should be balanced based on risk management and satisfaction of co-workers.

Tatani et al estimated that about 5 years are required from onset of dementia to the time a patient has difficulty in continuing a job and leaves the workplace. ${ }^{7}$ In this case, 4 years had passed. This shows that early diagnosis and support are important. For patients with dementia to continue their work, understanding of coworkers and environmental arrangements are needed, in addition to regular health checkups for screening of premature senility. Such policy considerations are required in future planning.

\section{Conclusion}

It is difficult to support a patient with dementia, to continue his/her job, especially FTD. We easily get impatient with his/her "going-my-way" behavior, however, we can change our mind and understood that the disease was the cause of his/her difficulty, not the person him/herself. This case report hopefully suggests a methodology; the case's work tasks and hours were changed to fit with her stereotypical behavior. This support in the workplace made it possible to continue job.

\section{Disclosure}

The authors report no conflicts of interest in this work.

\section{References}

1. The Ministry of Health, Labour and Welfare, Japan http://www.mhlw. go.jp/houdou/2008/07/h0710-1.html2015.8.25. Accessed September 1, 2021.

2. The Ministry of Health, Labour and Welfare, Japan. https://www. mhlw.go.jp/stf/seisakunitsuite/bunya/koyou_roudou/koyou/shougaisha koyou/06a.html. Accessed September 1, 2021.

3. Silvaggi F, Leonardi M, Tiraboschi P, Muscio C, Raggi A. Keeping people with dementia or mild cognitive impairment in employment: a literature review on its determinants. Int $J$ Environ Res Public Health. 2020;17:842. doi:10.3390/ijerph17030842

4. Sato S, Iwata K, Furukawa S, Matsuda Y, Hatsuse N, Ikebuchi E. The effects of the combination of cognitive training and supported employment on improving clinical and working outcomes for people with schizophrenia in Japan. Clin Practice Epidemiol Mental Health. 2014;10:18-27. doi:10.2174/1745017901410010018

5. Coraini A, Basciotta M. frontotemporal dementia as underlying cause of newly altered mental status in a 59-year-old female: a case presentation and literature review. J Community Hospital Internal Med Perspectives. 2020;10:446-451. doi:10.1080/20009666.2020.1787810

6. Neary D, Snowden JS, Gustafson L, et al. Frontotemporal lobar degeneration. A consensus on clinical diagnostic criteria. Neurology. 1998;51:1546-1554. doi:10.1212/WNL.51.6.1546

7. Taniya K, Ito $\mathrm{N}$ A study of job continuation for presenile dementia. Employment Support Organization for The Elderly and Persons with Disabilities. 2010;96. ISSN:1340-5527, J-GLOBAL ID:2010022292 42834356 (In Japanese).

\section{Publish your work in this journal}

The International Medical Case Reports Journal is an international, peer-reviewed open-access journal publishing original case reports from all medical specialties. Previously unpublished medical posters are also accepted relating to any area of clinical or preclinical science. Submissions should not normally exceed 2,000 words or 4 published pages including figures, diagrams and references. The manuscript management system is completely online and includes a very quick and fair peer-review system, which is all easy to use. Visit http://www.dovepress.com/testimonials.php to read real quotes from published authors. 